doi:10.12662/2359-618xregea.v8i2.p149-162.2019

ARTIGOS

\section{COMPORTAMENTO DE COMPRA DO CONSUMIDOR EM MERCADOS DE MODA INFORMAL}

\section{BEHAVIOR OF CONSUMER PURCHASE IN INFORMAL FASHION MARKETS}

\section{RESUMO}

Este estudo tem por objetivo analisar os fatores que influenciam o comportamento de compra do consumidor de mercados de moda informal. Adotou-se a metodologia quantitativa, com a utilização de um questionário estruturado, tendo ele sido dividido em um bloco com seis perguntas sobre o perfil sociodemográfico e outro com 11 perguntas acerca do comportamento do consumidor e as variáveis influenciadoras no processo de compra, aplicado de forma presencial, sendo a abordagem direcionada aos consumidores que apresentassem algum produto de compra. A pesquisa de campo foi realizada no Centro Fashion da cidade de Fortaleza, somando um total de 320 questionários válidos. O processo de análise constou das fases: levantamento das estatísticas descritivas iniciais, verificação da confiabilidade e validade das escalas, usando a consistência interna (Alpha de Cronbach), e por fim, foi conduzida uma Análise Fatorial Exploratória (AFE) para reduzir o número de variáveis. Os resultados alcançados mostram que a maioria das variáveis trabalhadas influencia a escolha do consumidor. Algumas variáveis realçam, no entanto, a importância que é dada ao fator econômico e ao poder de compra (fator preço), tornando evidente que o modelo do centro de moda informal representa a opção de o consumidor ter a oportunidade de compra além das necessidades básicas.

Zaíla Maria de Oliveira zailaoliveira@gmail.com Mestre em Marketing. Doutoranda no curso de Doutoramento em Ciências Empresariais pela Faculdade de Economia da Universidade do Porto - Portugal.

Célio Gomes de Lima Júnior celiogomesdelima@gmail.com Mestre em Administração pela Universidade de Fortaleza (Unifor). Professor do Centro Universitário Católica de Quixadá - Unicatólica. Quixadá - CE - BR.
Palavras-chave: Comportamento do Consumidor. Consumo de Moda. Decisão de Compra. Teoria do Comportamento Planejado - TCP.

\begin{abstract}
This study aims to analyze the factors that influence the consumer buying behavior in informal fashion markets. It was adopted a quantitative methodology, using a structured questionnaire, was divided into a block with 6 questions about the sociodemo-
\end{abstract}


graphic profile and another one with 11 questions about consumer behavior and variables influencing the purchase process, applied in a way the approach aimed at the consumers who presented some product of purchase. The field research was conducted at the Fashion Center of the city of Fortaleza, totaling 320 valid questionnaires. The analysis process consisted of the following phases: survey of the initial descriptive statistics, verification of the reliability and validity of the scales using the internal consistency (Cronbach's alpha), and finally, an Exploratory Factor Analysis (EFA) was conducted to reduce the number of variables. The results show that most of the variables worked influence consumer choice. Some variables emphasize, however, the importance given to the economic factor and purchasing power (price factor), making it clear that the model of the informal fashion center represents the option of the consumer to have the opportunity to purchase beyond basic needs.

Keywords: Consumer Behavior. Fashion Consumption. Buying decision. Theory of Planned Behavior - TPB.

\section{INTRODUÇÃO}

O comportamento humano tem sido motivo de estudos, tanto práticos quanto teóricos, objetivando um entendimento das ações realizadas pelos indivíduos em situações específicas. Observa-se que, com as necessidades básicas satisfeitas, como segurança, alimentação e higiene, os indivíduos procuram atender as necessidades de status e autorrealização. Nesse contexto, os produtos pertencentes ao segmento do luxo atendem aos anseios e às necessidades de realização pessoal.

Contudo, no segmento dos centros de vestuário popular no Brasil, as investigações realizadas têm vindo a demonstrar grandes movimentações econômicas em várias regiões do País. Na região Nordeste, os estados que têm apresentado maior destaque são Pernambuco e Ceará (BRAGA; ABREU; OLIVEIRA, 2015).
O crescimento observado no setor deve-se, em parte, à ampliação do número de indústrias de confecções de vestuário, à extensão dos espaços de comercialização, à expansão da produção e à geração de trabalho e de rendimentos para a população periférica (ALVES et al., 2009).

Nos dias atuais, o consumo apresenta novas configurações provocadas pela instabilidade dos comportamentos dos consumidores e a economia do país. Dessa forma, faz-se necessário compreender o panorama peculiar da sociedade moderna, com relação ao comportamento de compra do consumidor em mercados de moda popular brasileira.

O mercado da moda está em constante evolução, e a força que a moda tem conquistado no decorrer dos últimos anos no Brasil vem representando um elemento importante de identidade individual e expressão social. Em um contexto social e cultural, essa força configura-se por meio de mudança nas escolhas de um grupo de indivíduos. Esses grupos aderem ou não ao que a moda propõe de acordo com o poder aquisitivo real de cada ser humano. Como fator cultural, a moda reflete o status de uma pessoa em relação à outra; portanto, altera a identidade mundial e a identidade pessoal dentro da sociedade de consumo.

A moda é responsável por segmentar a sociedade em grupos de aceitação da transformação gerada por ela. O setor da moda ampliou o mundo dos negócios, o aumento da oferta de produtos e serviços, a concorrência acirrada entre as empresas, as mudanças econômicas e o aumento do poder de compra das classes B, C, D e E. Acontecimentos diversos desencadearam mudanças no comportamento dos consumidores e, consequentemente, no posicionamento de algumas empresas mais atentas ao mercado.

Diante da complexidade da relação entre o mercado de moda popular brasileira e o comportamento do consumidor de classe média, a Teoria do Comportamento Planejado (TCP) baseia-se no pressuposto de que os indivíduos tomam suas decisões de forma eminentemente racional e utilizam, sistematicamente, as infor- 
mações que estão disponíveis, considerando as implicações de suas ações antes de decidirem se devem ou não se comportar de determinada forma. Assim, a TCP proposta por Ajzen e Fishbein (1975) pode contribuir para entendimento dessa relação.

A perspectiva desta pesquisa é encontrar respostas para o questionamento: quais as variáveis que influenciam o comportamento de compra de pessoas de classe média em mercados de moda informal? Para tal, o objetivo principal é analisar os fatores que influenciam o comportamento de compra do consumidor de mercados de moda informal. E, como objetivos específicos, (i) descrever o perfil do consumidor (a) de moda informal do Centro Fashion em Fortaleza (ii), avaliando os motivos que levam o consumidor a comprar em centros de moda informal.

Abordando a influência do comportamento de compra de pessoas de classe média em mercados de moda informal, o presente estudo pretende preencher essa lacuna, analisando consumidores de um centro comercial popular. O propósito é que o resultado da pesquisa fornecerá informações para os gestores do segmento, contribuindo, dessa forma, para o desenvolvimento de novas estratégias comerciais.

O Centro Fashion está situado em Fortaleza (CE) e se configura como um dos maiores centros atacadistas de moda popular do Norte e Nordeste; possui 74 mil metros quadrados de área construída, com, aproximadamente, $5.500 \mathrm{mil}$ boxes, lojas e megalojas em que o foco é o comércio de peças no atacado, sem dispensar o varejo.

\section{REVISÃO DA LITERATURA}

\subsection{PROCESSO DE COMPRA DO CONSUMIDOR}

De acordo com Kotler e Keller (2012), o processo de compra inicia-se quando o consumidor sente a necessidade de ter algo, e esse processo possui algumas etapas pelas quais o consumidor passará antes, durante e depois da compra de algum bem ou serviço.

A compra de um determinado produto ou serviço ocorre por meio de um processo de tomada de decisão pela qual o consumidor opta por adquirir ou não um produto ou serviço, levando em consideração as diversas variáveis e percepções. O processo de compra inicia-se quando o consumidor sente a necessidade da aquisição de algo, e esse processo possui etapas por que o consumidor passará antes, durante e pós-compra de algum bem ou serviço.

O processo de compra é dado em etapas: a etapa do julgamento é caracterizada pela influência de representações sociais que valorizam ou não a intenção da compra e as expectativas a que a ela se refere; a etapa da compra é definida como um jogo de negociação no qual algumas variáveis, como o tempo disponível e o conhecimento das partes envolvidas, moldam a dinâmica da negociação; a etapa do uso é o momento em que a adequada operação do produto leva aos resultados esperados; por fim, na etapa de avaliação pós-compra, o consumidor conclui se suas expectativas foram satisfeitas, em uma comparação entre o que se esperava e o que foi obtido (GIGLIO, 2005).

Essas etapas certificam que, até o momento da compra, o consumidor passa por outras etapas anteriores, ocorrendo, ainda, o processo pós-compra. De posse dessa conclusão, faz-se necessário saber alguns fatores que influenciam o processo de decisão de compra dos consumidores.

Segundo Kotler e Keller (2012), o modelo do processo de decisão de compra do consumidor desenvolve-se em três estágios: pré-compra, estágio do consumo, estágio de pós-compra, que, por conseguinte, dão origem a cinco etapas: reconhecimento do problema, busca de informações, avaliação das alternativas, decisão de compra e comportamento pós compra. 
Figura 1 - Modelo das etapas do processo de decisão de compra

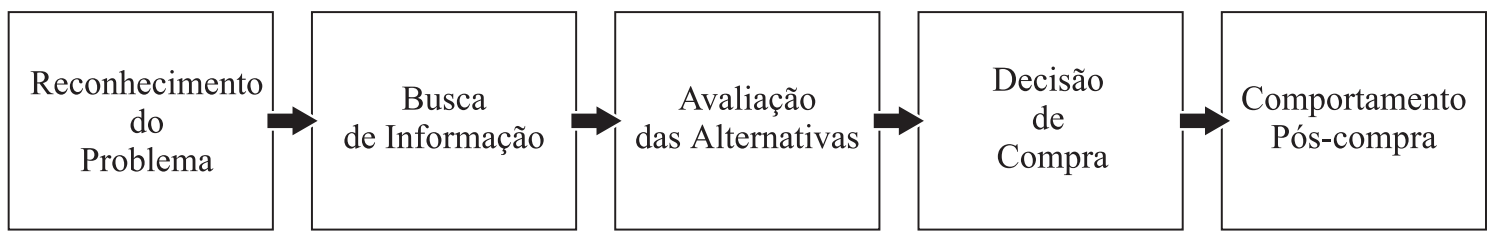

Fonte: Kotler e Keller (2012, p. 179).

\subsubsection{Reconhecimento do problema}

Segundo Kotler e Keller (2012, p. 179), "o processo de compra começa quando o comprador reconhece um problema ou uma necessidade desencadeada por estímulos internos e externos." Os estímulos internos vêm das necessidades da pessoa, tornando-se um impulso, e os estímulos externos são provocados pelo ambiente. Daí a importância da identificação das circunstâncias que determinam essas necessidades pelas empresas. Conforme Kotler e Keller (2012), os profissionais de marketing precisam identificar as circunstâncias que desencadeiam determinada necessidade pela coleta de informações entre vários consumidores. A identificação dessas circunstâncias pode desenvolver estratégias de marketing que despertem o interesse do consumidor.

\subsubsection{Busca de informações}

Segundo Schiffman e Kanuk (2009, p. 383), "a busca da pré-compra começa quando o consumidor percebe uma necessidade que pode ser atendida pela compra e pelo consumo de um produto." É comum ao consumidor interessado buscar maiores informações sobre possíveis produtos a serem comprados. Esse nível de interesse se divide em duas diferentes formas: na primeira, o consumidor é mais receptível às informações que chegam até ele e, na segunda, o próprio consumidor busca informações em diversas fontes. As fontes são as seguintes: pessoais (incluem família, amigos, vizinhos e outros conhecidos); comerciais (propaganda, vendedores, representantes, embalagens e mostruários), públicas (meios de comunicação em massa, organizações de classificação de consumo); expe- rimentais (manuseio, exame e o próprio uso do produto (KOTLER; KELLER, 2012)

Segundo Kotler e Keller (2012, p. 180), "a quantidade relativa e a influência dessas fontes de informação variam de acordo com a categoria de produtos e as características do comprador." Com isso, o consumidor recebe a maior parte das informações sobre um produto por meio de fontes informações comerciais.

\subsubsection{Avaliação das alternativas}

Com a avaliação de alternativas, o consumidor determina qual ou quais os produtos ele tem a intenção de comprar. Na visão de Kotler e Keller (2012, p. 181), "não existe um processo único usado por todos os consumidores, nem por um consumidor em todas as situações de compra." Os modelos mais atuais consideram que o consumidor forma julgamentos, principalmente em uma base racional e consciente. Na maioria dos casos, ao avaliar alternativas de compra entre concorrentes distintos e produtos com características e benefícios diferentes, as pessoas refletem nessa avaliação suas crenças e atitudes.

As crenças e as atitudes são aprendizados e experiências vividas ao longo da sua vida, que alguém as mantém a respeito de alguma coisa, influenciando as decisões de compra. Em relação à atitude, os autores afirmam que correspondem às avaliações, aos sentimentos e às tendências de ações duradouras, que podem ser favoráveis ou não a algum objeto ou ideia.

Segundo Schiffman e Kanuk (2009, p. 385), "fazer uma seleção a partir de uma amostra de marcas (ou modelos) possíveis é uma característica humana que ajuda a simplificar o processo de tomada de decisão", ou seja, o consumidor escolhe, entre uma marca ou outra, as 
que têm preferência e, a partir delas, determina os critérios para avaliar cada marca.

\subsubsection{Decisão de compra}

Normalmente, os consumidores não adotam uma regra no momento da decisão de compra. Muitas vezes, são levados pela emoção; porém, durante a avaliação, mesmo que o comprador decida por determinada marca ou modelo, dois fatores podem interferir entre a intenção e a decisão de compra. Ao formar a intenção de compra, ele pode passar por cinco subdecisões: decisão por marca, decisão por revendedor, decisão por quantidade, decisão por ocasião e decisão pela forma de pagamento. Logo, os consumidores não adotam, necessariamente, um único tipo de regra de escolha em suas decisões de compra (KOTLER; KELLER, 2012).
Segundo Kotler e Keller (2012), essa satisfação do cliente deriva da proximidade entre suas expectativas e o desempenho percebido do produto; se o produto não atende, plenamente, às expectativas, o cliente fica desapontado. $\mathrm{Na}$ insatisfação do consumidor em relação ao produto, ele toma ações que correspondem ao resultado que obteve. Um consumidor satisfeito voltará a comprar o produto e provavelmente o indicará para amigos e familiares como algo satisfatório. Já o cliente insatisfeito com o produto, além de procurar devolvê-lo, pode recorrer a ações públicas, redes sociais e advogados que representam, atualmente, uma ameaça para as empresas por sua rápida repercussão na sociedade.

Compreender o consumidor não é tarefa fácil, pois não depende apenas das ações das empresas, mas do conhecimento sobre suas motivações, das preferências, atitudes, classes

Figura 2 - Etapas entre a avaliação de alternativa e a decisão de compra

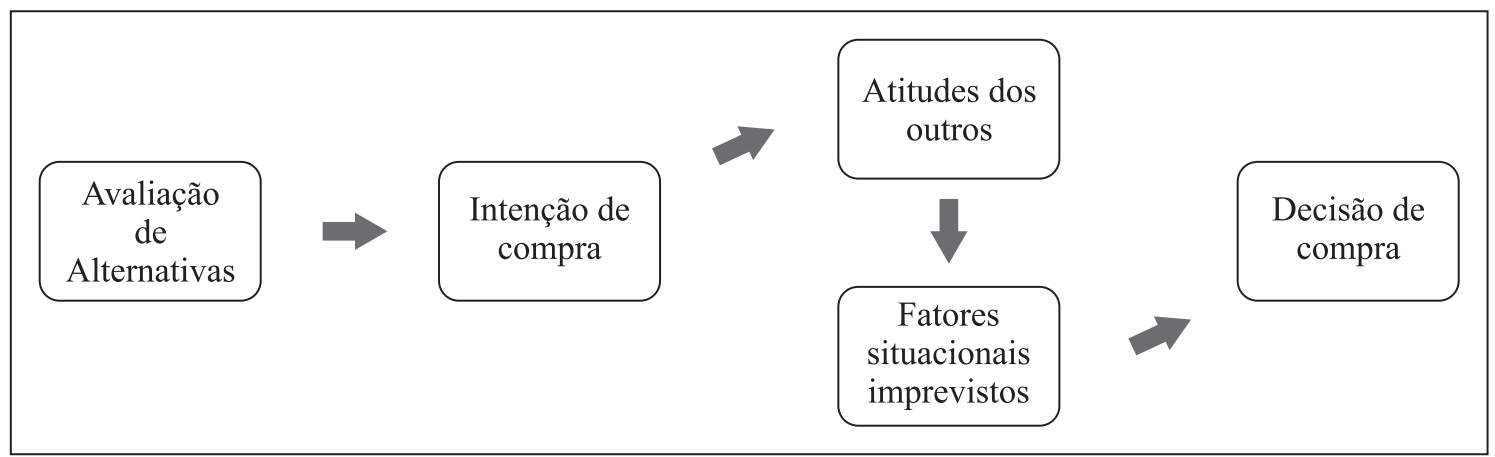

Fonte: Kotler e Keller (2012, p. 184).

\subsubsection{Comportamento pós-compra}

Depois da compra do produto, o consumidor o avalia por meio de suas expectativas. Existem três possíveis resultados dessas avaliações: 1) o desempenho real atende às expectativas, levando a um sentimento neutro; 2) o desempenho supera as expectativas, causando o que se conhece como a não confirmação positiva das expectativas (que leva à satisfação) e 3) o desempenho fica abaixo das expectativas, causando a não confirmação negativa das expectativas e insatisfação (SCHIFFMAN; KANUK, 2009, p. 393). sociais, dos grupos a que pertence, das necessidades, dos comportamentos na decisão de compra e de outros fatores que atuam sobre ele (SOLOMON, 2011).

\subsection{MODA E CONSUMO}

O consumo apresenta-se como um fenômeno-chave para a compreensão da sociedade contemporânea. Na vida social cotidiana, o consumidor ganha visibilidade por meio de traços no espírito do tempo, como, moda, objetos, produtos, serviços, design, marcas, grifes, shoppings, televisão, publicidade e comunicação de massa (ROCHA, 2005). 
Na moda, o consumo acontece pela necessidade de o indivíduo se expressar e pela necessidade de se sentir aceito dentro de grupo social. Os consumidores compram de acordo com sua renda. Segundo Frings (2012, p. 44), “A quantidade de dinheiro que os consumidores gastam com moda e outras mercadorias depende de sua renda. Uma vez que a renda afeta o consumo, ela é medida de três maneiras: renda pessoal, renda disponível e renda discricionária."

A renda pessoal é a renda bruta do consumidor; a renda disponível é a renda bruta menos os impostos, e a renda discricionária é o que resta depois de o consumidor ter pagado por suas necessidades básicas, como alimentação, moradia e transporte. $\mathrm{O}$ que sobra o consumidor pode gastar com outras necessidades ou desejos. Geralmente, as pessoas que gostam de roupas da moda são aquelas com poder aquisitivo alto e vontade de comprar marcas de luxo. Segundo Gaultier (1992 apud FRINGS, 2012, p. 66), "as vítimas da moda são as pessoas que seguem cega e estupidamente uma marca sem qualquer discernimento e sem qualquer análise."

Os consumidores estão buscando a última moda, compram sem pensar em adaptá-las para si. É possível, também, analisar os motivadores da compra do consumidor. Antigamente, a maioria das pessoas comprava roupas novas apenas quando surgia a necessidade, para uma ocasião especial ou porque as roupas estariam velhas ou desgastadas. Em média, a pessoa, simplesmente, não tinha condições de comprar mais do que as necessidades básicas. Atualmente, na sociedade ocidental, a renda discricionária é maior, e as pessoas podem comprar roupas novas com frequência (FRINGS, 2012, p. 70).

Os fatores analisados pelo consumidor para comprar um produto de moda são ser atraente, estar na moda, impressionar os outros, ser aceito por amigos, ser multiuso, ter conveniência e ter um valor percebido razoável. Atualmente, o desafio do profissional de moda está na criação, nas tendências e na satisfação dos desejos e expectativas do consumidor sobre um só produto, tornando-o comercial.

Considerando que a moda é um produto da divisão de classes, ela ocupa, frequentemente, as camadas consecutivas de classes sociais. De acordo Simmel (1988, p. 101), quando as classes inferiores começam a imitar as classes superiores e a se apropriar da sua moda, estas últimas passam a declinar daquelas preferências para adotarem outras novas. Contudo, ao mesmo tempo, na modernidade, a impaciência e o vai-e-vem fazem mudar a moda muito rapidamente entre as camadas sociais, arriscando abolir seu próprio sentido por uma difusão geral.

\subsection{TEORIA DO COMPORTAMENTO PLANEJADO - TCP}

A teoria do Comportamento Planejado (TCP), de forma geral, é o modelo social psicológico mais adequado para prever o comportamento humano (AJZEN; COTE, 2008), pois é baseada em poucas variáveis explicativas (AJZEN, 2002). A TCP baseia-se no pressuposto de que as pessoas fazem suas escolhas de forma sensata, utilizando as informações disponíveis e considerando as implicações de suas ações antes de tomarem suas decisões. Vale enfatizar que a TCP pode ser considerada um avanço da Teoria da Ação Racionalizada, visto que esta última apresentava uma limitação no que tange ao tratamento de comportamentos sobre os quais as pessoas tinham controle volicional incompleto (AJZEN, 2002).

Segundo Hoppe et al. (2012), a TCP é estruturada em três pontos: (i) nas crenças comportamentais; (ii) nas crenças normativas, e (iii) nas crenças sobre o controle. As crenças comportamentais tratam de uma atitude favorável ou desfavorável em relação ao comportamento. Já as crenças normativas referem-se às pressões sociais, ou seja, as expectativas do comportamento percebido sobre outros indivíduos (amigos, familiares). Essas crenças normativas, combinadas com a motivação pessoal em obedecer a diferentes regras, determinam a norma subjetiva que justifica a compra. Por último, as crenças sobre o controle se referem aos fatores que podem facilitar ou impedir o desempenho do comportamento. 
$\mathrm{Na}$ Teoria do Comportamento Planejado, o controle comportamental percebido influencia a intenção e o comportamento de compra. Assim, segundo Ajzen e Fishbein (1980), a importância coerente da atitude, da norma subjetiva e do controle comportamental percebido na predição da intenção sofre uma variedade condizente com os diferentes comportamentos e situações. Cada uma dessas crenças gera, respectivamente, a atitude em relação ao comportamento, à norma subjetiva e ao controle comportamental percebido (AJZEN, 2002; AJZEN; COTE, 2008). A combinação desses três construtos conduz a formação de uma intenção comportamental, que, segundo o modelo, é o influenciador direto do comportamento humano. Desse modo, admite-se que o poder da atitude, conforme a norma subjetiva e o controle percebido, é determinante da intenção do comportamento (AZJEN; COTE, 2008). A figura 3 mostra a proposta de Ajzen e Fishbein (1975). consumo feminino de moda no cenário brasileiro; testar as propriedades psicométricas e a validade da mensuração do instrumento no mercado brasileiro; e, por fim, testar o modelo escolhido, verificando seu poder de explicação dos antecedentes do comportamento da consumidora de moda.

Por fim, vale afirmar que a TCP é, hoje, o modelo dominante das relações atitude-comportamento, possibilitando a previsão acurada do comportamento das pessoas, a partir de um conjunto reduzido de variáveis antecedentes - atitude relativa ao comportamento, à norma subjetiva e ao controle percebido do comportamento (ARMITAGE; CHRISTIAN, 2003).

\section{METODOLOGIA}

Visando alcançar o objetivo proposto, foi realizada uma pesquisa exploratória. Desenvolveu-se uma pesquisa de caráter quantitativo,

Figura 3 - Teoria do Comportamento Planejado - TCP

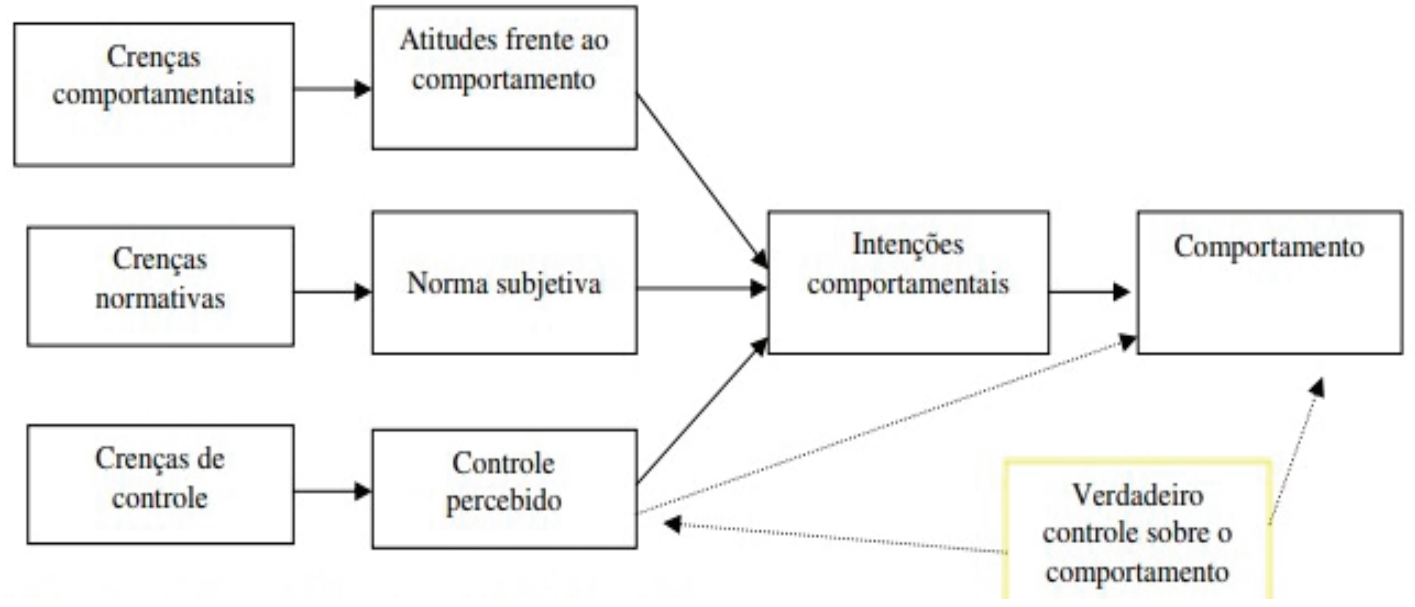

Fonte: Ajzen e Fishbein (1975).

Um exemplo de pesquisa que utilizou a teoria do comportamento planejado para avaliar o comportamento do consumidor de moda feminina foi o de Lima (2016). A pesquisa buscou identificar os antecedentes que explicam o comportamento do consumidor feminino de moda segundo a teoria escolhida; elaborar um modelo de questionário adequado à Teoria do Comportamento Planejado, direcionado ao quanto à abordagem do problema e, descritivo, quanto a seus objetivos (MALHOTRA, 2012), visando identificar os fatores que influenciam no processo de compra dos consumidores no mercado de moda informal.

O procedimento de amostragem não probabilística, por conveniência, foi utilizado junto a consumidores (as) que realizam compras no Centro Fashion da cidade de Fortaleza, 
somando um total de 320 questionários válidos. $\mathrm{Na}$ amostragem por conveniência, segundo Malhotra (2012), a seleção das unidades amostrais é determinada principalmente pelo pesquisador, buscando obter uma amostra de elementos convenientes ao desenvolvimento do propósito do estudo, o que se demonstrou adequado, visto que o foco é a mensuração de comportamentos de um grupo específico.

$\mathrm{O}$ instrumento de coleta utilizado foi o questionário estruturado dividido em dois blocos: sendo o primeiro, com 6 perguntas, para identificar o perfil do entrevistado, e o segundo, composto por 11 perguntas de múltipla escolha utilizando a escala de likert de 5 pontos, sobre o comportamento do consumidor e as variáveis influenciadoras no processo de compra. Dessa forma, o instrumento de pesquisa enquadra-se como um survey do tipo corte transversal (FREITAS et al., 2000). Importante salientar que tal instrumento passou por uma fase de pré-teste com professores da área e clientes do Centro Fashion.

A coleta de dados foi realizada no mês de maio de 2018, de forma presencial, uma vez que os autores optaram por abordar consumidores (as) que apresentassem alguma evidência de compra efetuada. Dessa forma, a verificação de questionários com data missing foi realizada no momento da aplicação da pesquisa. Depois da coleta e a digitação dos questionários em uma planilha de dados, as seguintes etapas foram adotadas durante as análises: levantamento das estatísticas descritivas iniciais, verificação da confiabilidade e validade das escalas usando a consistência interna (alpha de Cronbach), e, por fim, foi conduzida uma Análise Fatorial Exploratória (AFE) para reduzir o número de variáveis, agrupando-as em fatores representativos das originais que foram usadas como insumo para as análises desta pesquisa.

Para as análises estatísticas, foram utilizados os softwares Statistical Package for the Social Sciences ${ }^{\circledR}$ - SPSS 21.0. Inicialmente, realizaram-se, no SPSS, estatísticas descritivas simples (cálculo da frequência e percentuais de respostas) para identificar o perfil dos respondentes e a Análise Fatorial Exploratória, visando identificar os fatores representativos dos conjuntos de variáveis, ou seja, dos construtos em estudo. A utilização de softwares de pesquisas permite o aumento da qualidade do estudo devido ao uso de computadores, que facilita e melhora a demonstração dos resultados (FLICK, 2004).

Para verificar a adequação da utilização da AFE, foram realizados os testes de Kaiser-Meyer-Olkin (KMO) e de esfericidade de Barlett. $\mathrm{O}$ teste de $K M O$ permite verificar a adequação dos dados; os valores maiores que 0,6 indicam análise fatorial satisfatória; os valores entre 0,7 e 0,8 são bons; os valores entre 0,8 e 0,9 são ótimos, e os valores acima de 0,9 são excelentes (HUTCHESON; SOFRONIOU, 1999). Já o teste de esfericidade de Barlett testa a inexistência de correlação perfeita entre as variáveis (MALHOTRA, 2012). Em seguida, realizou-se a análise das comunalidades que identifica a proporção da variância que uma variável compartilha com todas as demais variáveis e, como regra, deve atingir valor superior a 0,6 e análise da variância total explicada que representa o quanto as variáveis explicam o construto, esperando-se valores acima de $60 \%$ (HAIR JUNIOR et al., 2009).

Após a definição dos fatores, verificou-se a confiabilidade de coerência interna dos construtos, por meio do coeficiente Alfa de Cronbach, que assume valores a partir de 0,7 como aceitáveis (HAIR JUNIOR et al., 2009).

\section{RESULTADOS}

O Centro de moda Informal em Fortaleza recebe, em média, 4 mil pessoas por semana vindas de todo o País, em especial, de estados como Piauí, Pernambuco, Maranhão, Pará, Bahia, Paraíba, Rio Grande do Norte, Amazonas, entre outros. Com um mix de produtos que varia de moda feminina, moda masculina, moda praia, calçados, moda infantil, moda íntima e acessórios, funciona sempre das $6 \mathrm{~h}$ da manhã, nas quartas-feiras, ao meio-dia das quintas-feiras; $14 \mathrm{~h}$ da tarde a $23 \mathrm{~h}$ da noite da sexta; e 6h da manhã dos sábados ao meio-dia dos domingos. 
O empreendimento possui uma ampla praça de alimentação com restaurantes e lanchonetes, salão de beleza, estacionamento para carros, motos, bicicletas e 130 vagas exclusivas para ônibus, hotel com 370 leitos, ambulatório, farmácia, caixas eletrônicos, banheiros, segurança, circuito interno de TV, rádio e disponibiliza carrinho de compras para os clientes. O objetivo é contribuir para o turismo de compra local. $\mathrm{O}$ empreendimento possui hospedagem própria, com 370 leitos, com o intuito de atender aos clientes do interior e de outros estados, que vêm a Fortaleza comprar mercadorias para a revenda.

O empreendimento conta, ainda, com pavimento completo de praça de alimentação, salão de beleza, lotéricas, caixas eletrônicos, lojas de aviamentos, lojas de tecidos, escritório virtual, espaço para desfiles, entre outros serviços. Outro diferencial é a disponibilidade de 130 vagas exclusivas para ônibus, além de vagas para carros, motos e bicicletas (CENTRO FASHION, 2018).

No que tange ao perfil dos respondentes, segundo o levantamento realizado em maio de 2018, observou-se uma predominância de respondentes do gênero feminino, com $78 \%$. Quanto ao estado civil, a maioria dos respondentes eram solteiros (54\%). A segunda maior fatia foi a dos casados, que correspondeu a $39 \%$ da amostra. Viúvos e divorciados somaram apenas $7 \%$ de representatividade na amostra. A maior parte dos respondentes não tinham filhos (53\%). Em seguida veio a parcela de respondentes que tinham apenas um filho (26\%). Em termos de escolaridade, a maior parte dos respondentes indicou estar no ensino superior incompleto, com $35 \%$, seguido dos respondentes com ensino superior completo $(25 \%)$. No que se refere à renda mensal familiar, 36\% afirmaram possuir entre 1 e 3 salários-mínimos (de $\mathrm{R} \$$ 974,01 até R\$2.922,00). Os respondentes com renda familiar entre 3 e 6 salários-mínimos (de $\mathrm{R} \$ 2.922,01$ até $\mathrm{R} \$ 5.844,00$ ) ocuparam a segunda posição de participação na amostra, as ocupações dos participantes da pesquisa também são expostos abaixo na tabela 1 .

Tabela 1 - Perfil dos respondentes do estudo

\begin{tabular}{|c|c|c|c|c|c|c|c|}
\hline & Variáveis & Qtde. & $\%$ & & Variáveis & Qtde. & $\%$ \\
\hline \multirow{2}{*}{ 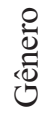 } & Masculino & 70 & $22 \%$ & \multirow{16}{*}{ 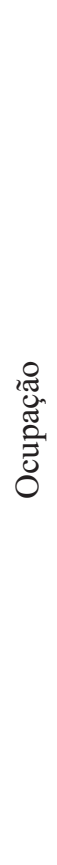 } & Estudante & 64 & $20 \%$ \\
\hline & Feminino & 250 & $78 \%$ & & Professor & 22 & $7 \%$ \\
\hline \multirow{4}{*}{ 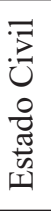 } & Solteiro & 173 & $54 \%$ & & Comerciante & 17 & $5 \%$ \\
\hline & Casado & 124 & $39 \%$ & & Auxiliar administrativo & 15 & $5 \%$ \\
\hline & Divorciado & 20 & $6 \%$ & & Empresário & 14 & $4 \%$ \\
\hline & Viúvo & 3 & $1 \%$ & & Servidor público & 13 & $4 \%$ \\
\hline \multirow{5}{*}{ 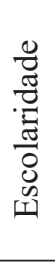 } & Ensino Fundamental & 7 & $2 \%$ & & Vendedor & 13 & $4 \%$ \\
\hline & Ensino Médio & 61 & $19 \%$ & & Esteticista & 11 & $3 \%$ \\
\hline & Ensino Superior Incompleto & 112 & $35 \%$ & & Administrador & 10 & $3 \%$ \\
\hline & Ensino Superior Completo & 79 & $25 \%$ & & Militar & 9 & $3 \%$ \\
\hline & Pós-Graduação & 61 & $19 \%$ & & Representante Comercial & 7 & $2 \%$ \\
\hline \multirow{5}{*}{ 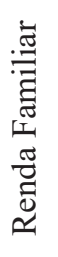 } & Até 1 salário-mínimo & 34 & $11 \%$ & & Assistente Administrativo & 7 & $2 \%$ \\
\hline & De 1 A 3 salários & 115 & $36 \%$ & & Dona de casa & 7 & $2 \%$ \\
\hline & De 3 A 6 salários & 78 & $24 \%$ & & Pedagogo & 6 & $2 \%$ \\
\hline & De 6 A 9 salários & 46 & $14 \%$ & & Secretário & 6 & $2 \%$ \\
\hline & De 9 A 12 salários & 47 & $15 \%$ & & Outros & 99 & $31 \%$ \\
\hline
\end{tabular}

Fonte: elaborado pelos autores (2019). 
Conhecido o perfil dos respondentes, realizou-se a análise dos fatores representativos dos conjuntos de variáveis, ou seja, dos construtos em estudo, isto, por meio da AFE. A confiabilidade da análise dos fatores depende, também, do tamanho da amostra (FIELD, 2009). Tabachnick e Fidell (2007) concordam que o ideal é ter, no mínimo, uma amostra de 300 respondentes para cada análise fatorial. Tais parâmetros validam, em um primeiro mo- mento, a amostra de 320 respondentes utilizada nesta pesquisa.

Inicialmente, realizou-se uma análise preliminar das 11 perguntas que compuseram o segundo bloco do questionário sobre o comportamento do consumidor e as variáveis influenciadoras no processo de compra. A tabela 2 mostra a mediana das afirmações das perguntas do segundo bloco do questionário.

Tabela 2 - Frequências das ocupações dos respondentes

\begin{tabular}{l|c}
\hline \multicolumn{1}{c|}{ Variáveis } & Mediana \\
\hline P1. Eu compro produtos no Centro Fashion porque meus familiares também compram. & 3 \\
\hline P2. Eu compro produtos no Centro Fashion porque minhas amigas também compram. & 3 \\
\hline P3. Eu compro produtos no Centro Fashion porque meus colegas de trabalho também compram. & 3 \\
\hline $\begin{array}{l}\text { P4. Eu compro produtos no centro Fashion porque as pessoas que são importantes para mim } \\
\text { também compram. }\end{array}$ & 3 \\
\hline P5. Eu compro produtos no Centro Fashion porque os preços são mais acessíveis. & 5 \\
\hline $\begin{array}{l}\text { P6. Eu compro produtos no Centro Fashion porque considero uma vantagem a relação } \\
\text { preço/qualidade. }\end{array}$ & 5 \\
\hline P7. Eu compro produtos no Centro Fashion por priorizar quantidade e não qualidade. & 1 \\
\hline $\begin{array}{l}\text { P8. Eu compro produtos no Centro Fashion por conseguir comprar mais peças que estão } \\
\text { dentro da moda e da tendência. }\end{array}$ & 4 \\
\hline P9. Eu prefiro comprar produtos no Centro Fashion por ser um local próximo à minha residência. & 3 \\
\hline P10. Eu prefiro comprar produtos no Centro Fashion pela comodidade do estacionamento? & 3 \\
\hline $\begin{array}{l}\text { P11. Eu prefiro comprar produtos no Centro Fashion por a marca do produto não influenciar } \\
\text { a minha decisão de compra. }\end{array}$ & 4 \\
\hline
\end{tabular}

Fonte: elaborado pelos autores (2019).

Em seguida, realizou-se uma análise fatorial exploratória pelo método de componentes principais, com o intuito de determinar o número mínimo de fatores que respondam pela máxima variância das opiniões coletadas para cada uma das onze diferentes afirmações apresentadas no questionário da pesquisa.

$\mathrm{Na}$ AFE, realizou-se a exclusão das variáveis não representativas, tomando como critério de exclusão a análise das comunalidades, assumindo que valores menores que 0,5 são insatisfatórios para a análise fatorial e, portanto, devem ser excluídos do modelo. Entre as 11 variáveis, 3 delas apresentaram comunalidade abaixo desse patamar. As variáveis foram excluídas, e a análise fatorial deve ser realizada novamente (SCHAWB, 2007), pois a baixa comunalidade entre um grupo de variáveis é um indício de que elas não estão linearmente correlacionadas e, por isso, não devem ser incluídas na análise fatorial (FIGUEIREDO FILHO; SILVA JÚNIOR, 2010). Neste estudo, excluíram-se as variáveis: P7 (comunalidade= 0,249); P8 (comunalidade $=0,398$ ) e P11 (comunalidade $=0,343$ ); em seguida, foi realizada, novamente, a análise fatorial.

A conveniência do modelo foi justificada pelo teste de esfericidade de Bartlett que obteve um valor da estatística qui-quadrado aproximadamente em 796,825, com significância de 0,000 , rejeitando-se a hipótese nula de que não há correlação entre as variáveis, e a medida de adequação da amostra de Kaiser-Meyer-Olkin (KMO), cujo alto valor 0,761 , indica que a téc- 
nica é apropriada para a análise dos dados (MALHOTRA, 2012; HAIR JUNIOR et al., 2009).

A extração dos fatores rotacionados pelo processo Varimax resultou na seleção de três fatores principais, os quais, de acordo com o critério da raiz latente, possuem, individualmente, autovalores superiores a um. Em conjunto, os três fatores identificados correspondem a $71 \%$ da variância total dos dados coletados.

A tabela 3, além das informações expostas anteriormente, apresenta as cargas fatoriais cujos valores indicam as correlações entre as afirmações apresentadas no questionário e os fatores extraídos pela técnica de análise. Para garantir a confiabilidade interna dos três constructos resultantes, extraiu-se o coeficiente alfa de Cronbach $(\alpha)$ para cada um deles. Todos os coeficientes calculados são adequados, uma vez que, sendo $\alpha>0,700$, segundo Hair Junior et al. (2009) e Malhotra (2012), torna possível a utilização da escala somada dos itens que compõem um fator.

Tabela 3 - Resultados da análise fatorial exploratória e confiabilidade interna dos fatores gerados

\begin{tabular}{|c|c|c|c|}
\hline \multicolumn{2}{|c|}{$\begin{array}{l}\text { Teste de Esfericidade de Bartlett Qui-quadrado } \\
\text { aproximado }=796,825 \text {, significância }=0,00\end{array}$} & \multicolumn{2}{|c|}{$\begin{array}{l}\text { Medida de Adequação da amostra (KMO) = } \\
0,761\end{array}$} \\
\hline Fator & \multicolumn{2}{|c|}{ Componentes Principais } & $\begin{array}{c}\text { Cargas } \\
\text { Fatoriais }\end{array}$ \\
\hline \multirow{4}{*}{ Social } & \multicolumn{2}{|c|}{ P1. Eu compro produtos no Centro Fashion porque meus familiares também compram. } & 0,845 \\
\hline & \multicolumn{2}{|c|}{ P2. Eu compro produtos no Centro Fashion porque minhas amigas também compram. } & 0,840 \\
\hline & \multicolumn{2}{|c|}{$\begin{array}{l}\text { P3. Eu compro produtos no Centro Fashion porque meus colegas de trabalho } \\
\text { também compram. }\end{array}$} & 0,792 \\
\hline & \multicolumn{2}{|c|}{$\begin{array}{l}\text { P4. Eu compro produtos no centro Fashion porque as pessoas que são } \\
\text { importantes para mim também compram. }\end{array}$} & 0,850 \\
\hline \multicolumn{4}{|c|}{ Percentual de variância total explicada $=39 \%$} \\
\hline \multicolumn{4}{|c|}{ Alfa de Cronbach $=0,864$} \\
\hline Fator & Component & Principais & $\begin{array}{c}\text { Cargas } \\
\text { Fatoriais }\end{array}$ \\
\hline \multirow[b]{2}{*}{ Preço } & \multicolumn{2}{|c|}{ P5. Eu compro produtos no Centro Fashion porque os preços são mais acessíveis. } & 0,885 \\
\hline & \multicolumn{2}{|c|}{$\begin{array}{l}\text { P6. Eu compro produtos no Centro Fashion porque considero uma vantagem a } \\
\text { relação preço/qualidade. }\end{array}$} & 0,881 \\
\hline \multicolumn{4}{|c|}{ Percentual de variância total explicada $=17 \%$} \\
\hline \multicolumn{4}{|c|}{ Alfa de Cronbach $=0,696$} \\
\hline Fator & Component & Principais & $\begin{array}{l}\text { Cargas } \\
\text { Fatoriais }\end{array}$ \\
\hline \multirow[t]{2}{*}{ Comodidade } & \multicolumn{2}{|c|}{$\begin{array}{c}\text { P9. Eu prefiro comprar produtos no Centro Fashion por ser um local próximo } \\
\text { à minha residência. }\end{array}$} & 0,852 \\
\hline & \multicolumn{2}{|c|}{ P10. Eu prefiro comprar produtos no Centro Fashion pela comodidade do estacionamento. } & 0,71 \\
\hline \multicolumn{4}{|c|}{ Percentual de variância total explicada $=15 \%$} \\
\hline & Alfa de Cronb & $\mathrm{ch}=0,413$ & \\
\hline
\end{tabular}

Fonte: elaborado pelos autores (2019).

\section{CONCLUSÕES}

Os resultados deste estudo sugerem que, em termos de perfil, o consumidor de moda informal do Centro Fashion, em Fortaleza, é composto por mulheres solteiras, com escolaridade no ensino superior incompleta, e renda mensal familiar entre um e três salários-mínimos. Em número menor, estão os indivíduos casados, com ensino superior completo e rendi- 
mento entre três e seis salários-mínimos.

Revisitando os objetivos de investigação, identificou-se que o comportamento de compra dos consumidores de mercados de moda informal é influenciado, de forma significativa, pelo fator preço, uma vez que as variáveis que apresentam as maiores médias são "eu compro produtos no Centro Fashion porque os preços são mais acessíveis" e "eu compro produtos no Centro Fashion porque considero uma vantagem a relação preço/qualidade". Por outro lado, verificou-se que a comodidade representa um fator de importância atribuída, sendo a variável relativa à proximidade com a residência $\mathrm{e}$ a facilidade de estacionamento como motivo de escolha para o consumidor comprar em locais como os centros de moda informal.

No que concerne ao fator social, para o consumidor de moda informal, os familiares, amigos e pessoas com significativa importância têm efeito positivo, contribuindo, assim, com a atitude em face da escolha do local para realizar suas compras. Para esse fator, a variável menos relevante se refere à influência dos colegas de trabalho em sua escolha.

Em síntese, os resultados alcançados mostram que a maioria das variáveis aqui trabalhadas influencia, de alguma maneira, a escotha do consumidor. Algumas variáveis realçam, no entanto, a importância que é dada ao fator econômico e ao poder de compra (fator preço), tornando evidente que o modelo do centro de moda informal representa a opção de o consumidor ter a oportunidade de gastar com necessidades além das básicas, como alimentação e saúde.

Vale ressaltar que as atitudes das pessoas são formadas pelas experiências de vida, e que o respeito e a credibilidade que o consumidor tem por alguém representa um fator de influência em suas decisões de compra. Tal como foi evidenciado na revisão da literatura, ao formar a intenção de compra, o consumidor pode passar por cinco subdecisões: decisão por marca, decisão por revendedor, decisão por quantidade, decisão por ocasião e decisão pela forma de pagamento; não significa, porém, que irá adotar, necessariamente, uma única regra de escolha em suas decisões de compra (KOTLER; KELLER, 2012).

A pesquisa traz a contribuição do emprego da Teoria do Comportamento Planejado na área de moda informal no mercado da cidade de Fortaleza. Uma vez que os estudos do comportamento dos consumidores são, por regra, sujeitos a alterações em função da amostragem e do período em que são realizados, os resultados obtidos apenas se aplicam no contexto das características demográficas dessa amostra e não podem ser generalizados.

Contudo, este estudo fornece algumas pistas aos gestores para reconhecer a importância e o impacto potencial dos espaços de compras no mercado da moda informal associado a uma adequada abordagem da oferta.

Finalmente, será válido apresentar sugestões de investigação futura. Sugere-se, portanto, replicar a investigação a uma amostra representativa do consumidor que realiza suas compras para revenda, aprofundando o estudo sobre os impactos que o Centro Fashion tem na economia informal.

\section{REFERÊNCIAS}

AJZEN, Icek. Perceived Behavioural Control, Self-Efficacy, Locus of Control and the Theory of Planned Behaviour. Journal of applied social psychology, v. 32, p. 665-683, 2002.

AJZEN, Icek; COTE, N. Gilbert. Attitudes and the prediction of behavior. In: CRANO, William D.; PRISLIN, Radmila (ed.). Attitudes and attitude change. New York: Psychology Press, 2008. p. 289-311.

AJZEN, Icek; FISHBEIN, Martin. Belief, attitude, intention and behavior: an introduction to theory and research. [S. l.: s. n.], 1975.

AJZEN, Icek; FISHBEIN, Martin. Understanding attitudes and predicting social behaviour. [S. l.: s. n.], 1980. 
ALVES, Rosiane Pereira et al. Moda e desenvolvimento local: reconversões culturais na criação e confecção do jeans em Toritama-Pernambuco. 2009. 100 f. Dissertação (Mestrado em Extensão Rural e Desenvolvimento Local) - Universidade Federal de Pernambuco, Recife, PE, 2009.

ARMITAGE, C. J.; CHRISTIAN, J. From Attitudes to Behavior: basic and applied research on the theory of planned behavior. Current Psychology, v. 22, n. 3, p. 187-195, 2003.

BRAGA, Iara; ABREU, Maria José; OLIVEIRA, Madalena. O mercado de moda popular brasileira: os centros de comercialização de vestuário popular na região Nordeste do Brasil. In: CONGRESSO INTERNACIONAL DE NEGÓCIOS DA MODA (CINM), 3., 2015, Porto, Portugal. Anais [...]. Porto, Portugal: Instituto Brasileiro de Moda, 2015. p. 1-22.

CENTRO FASHION FORTALEZA. Site institucional. Disponível em: http://www.centrofashion.com.br/centro-fashion/. Acesso em: 22 maio 2018.

FIELD, Andy. Descobrindo a estatística usando o SPSS-2. Porto Alegre: Bookman, 2009.

FIGUEIREDO FILHO, Dalson Brito; SILVA JÚNIOR, José Alexandre da. Visão além do alcance: uma introdução à análise fatorial. Opinião pública, v. 16, n. 1, p. 160-185, 2010.

FREITAS, Henrique et al. O método de pesquisa survey. Revista de Administração da Universidade de São Paulo, v. 35, n. 3, p. 105$112,2000$.

FRINGS, Gini Stephens. Moda: do conceito ao consumidor. 9. ed. Porto Alegre: Bookman, 2012.

GIGLIO, Ernesto Michelangelo. O Comportamento do Consumidor. 3. ed. São Paulo: Thomson, 2005.
HAIR JUNIOR, Joseph F. et al. Análise multivariada de dados. Porto Alegre: Bookman, 2009.

HOPPE, Alexia et al. Comportamento do consumidor de produtos orgânicos: uma aplicação da teoria do comportamento planejado. Revista Base (Administração e Contabilidade) da UNISINOS, v. 9, n. 2, p. 174-188, 2012.

HUTCHESON, Graeme D.; SOFRONIOU, Nick. The multivariate social scientist: Introductory statistics using generalized linear models. [S.l.]: Sage, 1999.

KOTLER, Philip; KELLER, Kevin Lane. Administração de marketing. 14. ed. São Paulo: Pearson Prentice Hall, 2012.

LIMA, Maria Paula Corrêa Mangabeira de. Comportamento do consumidor feminino de moda: uma pesquisa empírica aplicando a teoria do comportamento planejado. Projetos, dissertações e teses do Programa de Doutorado e Mestrado em Administração, v. 5, n. 1, p. $1-98,2016$.

MALHOTRA, Naresh K. Pesquisa de marketing: uma orientação aplicada. Porto Alegre: Bookman, 2012.

ROCHA, Everardo. Totemismo e mercado: notas para uma antropologia do consumo. Logos, v. 3 , n. 2 , p. 55-57, 2005.

SCHAWB, A. J. Eletronic Classroom. 2007. Disponível em: http://www.utexas.edu/ssw/ eclassroom/schwab.html. Acesso em: 10 jan. 2018.

SCHIFFMAN, Lean G.; KANUK, Leslie L. Comportamento do consumidor. 9. ed. Rio de Janeiro: LTC, 2009.

SIMMEL, Georg. La tragédie de la culture et autres essais. Paris: Petite Bibliothèque Rivages, 1988. 
SOLOMON, Michael R. O Comportamento do Consumidor: comprando, possuindo e sendo. 9. ed. Porto Alegre, Editora Bookman, 2011.

TABACHNICK, Barbara G.; FIDELL, Linda S. Using multivariate statistics. [S.l.]: Allyn \& Bacon/Pearson Education, 2007. 